\title{
La caída de la tiranía de Falaris de Agrigento en Deipnosofistas de Ateneo: intrigas amorosas y «extraños» oráculos
}

\author{
The fall of the tyranny of Phalaris of Agrigento in Athenaeus' \\ Deipnosophists: love intrigues and «strange» oracles
}

\author{
Giuliana Besso*
}

\begin{abstract}
RESUMEN
El artículo tiene como objetivo analizar, a partir de un pasaje de Deipnosofistas de Ateneo (13.602a-b), el episodio de una tentativa de tiranicidio por los dos amantes

Caritón y Melanipo contra Falaris de Agrigento, relatado también por Eliano (Varia Historia 2.4). Una especial atención se presta a la cita de textos oraculares de Delfos, que son pruebas válidas de una tradición sobre un Falaris magnánimo y clemente y que, aun en el caso de no poder demostrar su valor como fuente histórica, son un testimonio muy importante del papel del veredicto oracular en la formación de la tradición sobre las tiranías de Sicilia.
\end{abstract}

PALABRAS CLAVE:

Tiranicidio, Falaris, Ateneo, oráculos, homoerotismo, Caritón y Melanipo.

\begin{abstract}
Starting from a passage of Athenaeus' Deipnosophists (13.602a-b), this contribution aims to analyze the story of the attempt to kill Phalaris, tyrant of Agrigentum, by Chariton and Melanippus, also described by Aelian (Varia Historia 2.4). Particular attention is paid to the quotation of oracular responses from Delphi, proving a tradition of a noble and clement Phalaris; such oracles cannot be surely considered historical sources, but they show the importance of oracular verdict in the constitution of tradition on tyrannies in archaic Sicily.
\end{abstract}

\section{KEYWORDS:}

Tyrannicide, Phalaris, Athenaeus, oracles, homoeroticism, Chariton and Melanippus.

* Dipartimento di Filologia, Linguistica e Tradizione classica «A. Rostagni», Università degli Studi di Torino (Via S. Ottavio 20, 10124 Torino. Italia). E-mail: giuliana.besso@ unito.it.

Artículo basado en la comunicación leída el 27 de Mayo de 2009, en la VIII edición del Encuentro de Jóvenes Investigadores de Historia Antigua de la Universidad Complutense de Madrid. 
Este trabajo nace de una investigación en curso acerca de la formación de la tradición sobre el tema del tiranicidio en el mundo antiguo. En relación con el tema del oráculo, parece muy interesante el pasaje de Deipnosofistas de Ateneo (siglos II-III d.C.) relativo al episodio de una tentativa de tiranicidio contra Falaris de Agrigento. Se trata de un relato tardío de un episodio posiblemente emplazado unos 750 años antes, alrededor de la mitad del siglo VI a.C. El pasaje de Ateneo y las otras fuentes que relatan la historia serán el punto de partida para algunas reflexiones sobre la construcción de la tradición y por consiguiente sobre el papel de las citas oraculares. Ellas, en mi opinión, pueden proveer útiles indicaciones sobre los tiempos y sobre los modos de la creación de varias tradiciones relativas al estereotipo del tiranicida y también de una imagen 'alternativa' en gran medida 'positiva' —en italiano, 'buonista'; Eliano la define como philanthropía — del tirano Falaris.

Ateneo, en el libro 13 de su Deipnosofistas (13.602a-b), hablando de las relaciones homoeróticas, indica cómo éstas han contribuido en la historia al derribo de numerosas tiranías. Se trata de un tema que él extrae directamente del Banquete de Platón, su fuente privilegiada, pero que desarrolla presentando ejemplos históricos que nunca anteriormente han sido puestos en paralelo: el Batallón Sagrado de Tebas, el atentado contra los Pisistrátidas en Atenas, y la historia de amor entre Caritón y Melanipo en Agrigento, en Sicilia. Los tres hechos tienen en común amores entre jovencitos y delitos de sangre, pero es al tercero al que el autor dedica un mayor espacio, apoyándose también en otra fuente, el Diálogo sobre cuestiones de amor (Erotikà Pathemata) de Heráclides Póntico. Caritón, enamorado de Melanipo, habría conspirado con él contra el tirano de Agrigento Falaris, pero su complot habría sido desactivado por el tirano mismo, que los habría sometido a continuación a tortura, para que revelasen los nombres de sus cómplices. Ellos no sucumbieron y Falaris, ablandado por lástima, los liberó con elogios por su valiente comportamiento. Tal gesto generoso sirvió a Falaris para posponer el momento de la muerte, sancionado por el oráculo de Apolo, quien se pronunció de este modo ante los que iban a interrogarlo con la intención de derribar la tiranía en la ciudad siciliana. Pero Ateneo añade además que el dios pronunció un oráculo también para los partidarios de Caritón, y de manera completamente particular, ya que expresó una profecía, contrariamente a sus costumbres de empleo del tradicional dístico elegíaco, en la que el pentámetro fue puesto antes del hexámetro, según un uso que literariamente será retomado solamente en Atenas por Dionisio Calco. El texto decía: «La Suerte sonríe a Caritón y a Melanipo, ejemplos de divi-

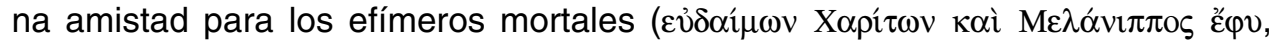

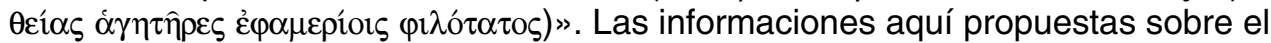
episodio representan, en gran parte, las únicas noticias en nuestra posesión, a excepción del mismo relato que se encuentra en Eliano, más o menos contemporáneo de Ateneo (Var.Hist. 2.4), mucho más rico en detalles y envuelto en el estilo anecdótico que caracteriza su obra: Melanipo, implicado en un proceso contra un amigo del tirano, fue amenazado por éste por no haber retirado la acusación; tras su negativa y a consecuencia de la injerencia de Falaris, Melanipo perdió el caso y pidió al amante Caritón unirse a él para derrotar al tirano. Caritón, aun es- 
tando de acuerdo, trató de tomarse su tiempo y decidió actuar por su cuenta, para preservar al enamorado de eventuales represalias en caso de que las cosas no hubieran salido bien. Llegado el momento de la acción, Caritón atacó a Falaris con un puñal, pero fue parado inmediatamente por los guardaespaldas del tirano, llevado a prisión y sometido a tortura. Frente a ésto, Melanipo decidió autoincriminarse y revelar ser él quien había tramado la conjuración como venganza por las injurias sufridas. Falaris, movido por la admiración, liberó a ambos imponiéndoles abandonar Agrigento y Sicilia aquel mismo día, aunque podían seguir disfrutando de los ingresos de sus posesiones. A continuación, Eliano concluye: «la Pitia exaltó a los dos y su amistad con los siguientes versos: 'modelo de divina amistad

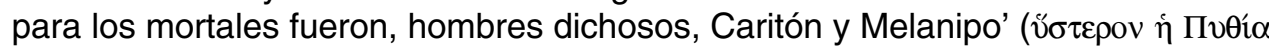

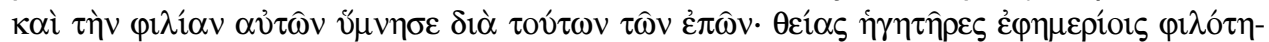

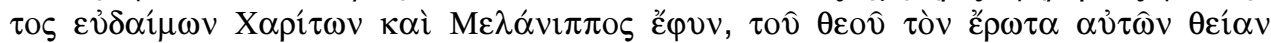

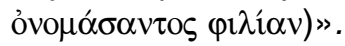

Este es en síntesis el hecho del que partimos; sin embargo, para completar la premisa hace falta dar todavía algunas indicaciones relativas a la tiranía de Falaris, cuyos rasgos históricos son difícilmente localizables bajo el velo de leyenda que se ha creado con el tiempo en torno a su figura. Falaris tomó el poder en Agrigento probablemente una década después de su fundación - como colonia de Rodas o bajo colonia de Hiela, pero las dos hipótesis pueden coexistir si se suponen dos grupos de colonos y dos fundadores-, alrededor del 570 a.C., y lo conservó hasta el 556/55 a.C. o 555/54 a.C., cuando fue derrotado por un motín popular. Según Aristóteles (Pol. 1310b 25), subió al poder, como los tiranos jónicos, partiendo de los cargos públicos -ek ton timon; la ciudad tenía anteriormente un régimen oligárquico-. Las modalidades son explicadas en las Estratagemas de Polieno (5.1.1-4). La autenticidad de estos relatos, muy precisos en lo que concierne a la topografía y algunas informaciones - hasta el punto de hacer pensar en acreditadas fuentes como Filisto o Timeo, pero también Éforo y la historiografía del siglo IV (Murray 1992: 47-60; Luraghi 1994: 31 ss.)-, no es del todo segura, sin embargo, ya que versiones similares a ésta aparecen también para otros tiranos, y hacen sospechar la existencia de anécdotas sobre el argumento, que adquirió ya en la antigüedad carácteres estereotipados.

Las Estratagemas de Polieno revelan, sin duda alguna, la influencia de la historiografía del siglo IV a.C., especialmente de Timeo, que realizó una racionalización de los datos que se remontan a las antiguas tradiciones orales nacidas dentro de las aristocracias locales $-\mathrm{y}$ por tanto ferozmente hostiles a la tiranía- y al mismo tiempo llenó las lagunas de la tradición insertando detalles, a menudo inventados, por analogía con otros hechos. Este elemento podría explicar, sin duda, las analogías y los casos parecidos presentados por Ateneo y Eliano a propósito de nuestra historia. Los caracteres esenciales con los que la figura de Falaris es trazada por la tradición son: astucia, ferocidad y aislamiento (Luraghi 1994: 33), expresados en particular en la historia del toro de bronce, obra de Perilao, episodio que lo describe como tirano cruel, a quien se hace ya referencia en la primera Pitica de Píndaro (1.185-188). Mucho más tarde, en Luciano (Falaris 1.1), un Falaris ya falso comunica haber encargado a embajadores entregar a Apolo délfico el toro 
(Bianchetti 1987: 111). De la amplia difusión de este carácter se tiene, sin embargo, la prueba en Aristóteles (Eth.Nic. 1148b 23-24), que de algún modo da cuenta de un proceso de creación de la tradición que, como se ha dicho, se desarrolla a través de los siglos $\mathrm{V}$ y IV a.C.

Del resto del relato de Polieno y de los datos arqueológicos se puede deducir que el componente religioso tuvo un papel fundamental en la política del tirano (Bianchetti 1987: 41), como por lo demás era natural, considerando la estrecha unión entre culto - y centros cultuales - y poder político en la antigüedad griega. Ella sirvió principalmente para llevar a cabo la unidad política y cultural entre coIonos e indígenas. En este sentido, se entienden, por lo tanto, el fomento del culto de Deméter y Core y el papel clave de la saga de Minos, Dédalo y Cócalo que serían prueba de un sustrato indígena que recordaría una importante penetración micénica en Sicilia. En realidad, la saga de Dédalo y Cócalo hacía las veces de metáfora de la relación entre griegos y sicanos y representaba la base para una acción propagandística dirigida a justificar las pretensiones territoriales de expansión (Luraghi 1994: 46-49). En particular desde su primera aparición en la literatura, precisamente en Píndaro, la figura de Falaris está caracterizada por un elemento mítico que lo conecta al personaje de Minos. De un estudio exhaustivo de los temas que definen la tradición emerge que muchos de los aspectos paradigmáticos que caracterizan el personaje de Falaris pueden ser reconducidos al mito cretense de Minos, usado de diferentes maneras - a partir de finales del siglo VI y principio del siglo $\mathrm{V}$ a.C. y conjuntamente a la figura del mítico rey sicano Cócalo, para legitimar las pretensiones de Agrigento sobre el territorio circundante y ya presente en Sicilia dentro del patrimonio cultural de la ciudad de Gela, madre patria de Agrigento (Luraghi 1994: 46). En todo caso, me parece de cualquier modo significativo que también en Heródoto resulte claro que la presencia del mito de Minos en Sicania era ya conocida en Grecia cuando, poco antes de la invasión de Jerjes, la Pitia sirvió para desaconsejar a los cretenses la participación en la coalición anti-persa (Hdt. 7.169-70). Los cretenses se presentaron en Sicilia después de que ya Minos llegara en busca de Dédalo, asediaron Camicos sin éxito y a su regreso, cogidos por sorpresa por una tempestad, fueron obligados a pararse y a fundar algunas ciudades ${ }^{1}$.

Entramos en el meollo de la cuestión del empleo 'político' del oráculo y su papel central para la formación de la tradición sobre las tiranías arcaicas (Araújo Caldas 2003; Parker 2000; lles Johnston y Struck 2005). Es oportuno indicar que, como ya ha sido subrayado más veces anteriormente, no pretendemos ver en el episodio narrado por Ateneo y Eliano -y señalado por Plutarco (Erot. 760b-c) y Heráclides Póntico (Erotikà Pathemata, fr. 65 Wehrli) - un testimonio histórico. Por otro lado, toda la tradición sobre Falaris está caracterizada por rasgos novelescos y tópicos. Me parece, sin embargo, importante reflexionar precisamente sobre la cita de los veredictos de los oráculos, auténticos o no, hecha por los dos autores, lo que nos conduce a re-evaluar el modo en que una Antigüedad ya remota podía

1 Sobre el valor de los oráculos en la obra de Heródoto, véase Crahay (1956). 
ser reexaminada muchos siglos después y en un contexto extraordinariamente diferente. Otra premisa puede ser que los mismos autores Ateneo y Eliano han sido utilizados más veces por los estudiosos como fuente digna de crédito, en particular el primero; precisamente Ateneo, en relación al tema del tiranicidio, es, en efecto, la fuente principal de los famosos skolia, los epigramas para los tiranicidas atenienses probablemente nacidos en un ámbito simposíaco (15.695a; ver BraundWilkins 2000).

Ateneo tenía, pues, óptimas fuentes, y aquí cita explícitamente al menos tres de ellas: el peripatético Jerónimo; el alumno de Aristóteles Heráclides Póntico, intermediario quizás también de la versión de otros episodios de la vida de Falaris, como por ejemplo el encuentro con Pitágoras y Ábaris presente en Jámblico; y el poeta del siglo $\mathrm{V}$ a.C. Dionisio Calco. Aunque amenizados con un aire novelesco, encontramos todos los caracteres del mundo griego arcaico en su relato: la historia de amor entre jovencitos, el intento de tiranicidio para vengar una ofensa padecida —común también por ejemplo al relato de Tucídides del tiranicidio ateniense-, el librarse del peligro por parte del tirano que exhibe su crueldad con la tortura del conspirador, el recurso al oráculo como interprete de hechos ya ocurridos o como consejero. Es del todo comprensible que la profecía oracular (Miletti 2004: 217), que concierne acontecimientos, datos reales, y comunica no verdades metafísicas, sino fenoménicas, históricas, revele en sustancia algo que el hombre no sabe, en un juego continuo entre el mensaje, en todo caso verdadero, de la profecía y la tergiversación del intérprete. Este último elemento, notablemente subra-

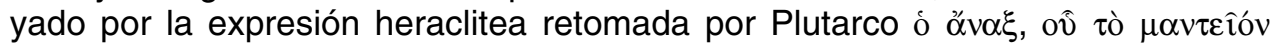

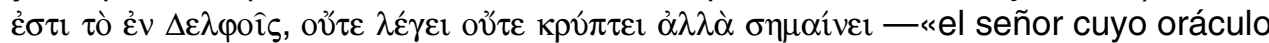
reside en Delfos no habla y no esconde, pero 'significa', habla por señas" (De Pyth.Orac. 404d 9-10 = fr. 93 Diels-Kranz)-, por una parte nos puede ayudar a comprender que no podemos hablar absolutamente de un oráculo 'interesado', como en muchos casos se ha creído al menos por los testimonios de Heródoto. En segundo lugar, el aspecto aparentemente simplista, si no inútil, del texto de la profecía, como puede ser el nuestro, no implica necesariamente que la cita tenga carácter ficticio.

¿Tuvo Delfos parte en la caída de la tiranía de Falaris? ¿Y puede nuestro oráculo, de algún modo, testimoniar que la Grecia continental tuvo un papel en la caída de las tiranías arcaicas en Magna Grecia? Que Delfos conociera las vicisitudes de la Magna Grecia - como ha sido probado también por el oráculo herodoteo citado anteriormente-, aunque con mucha prudencia, no podemos excluirlo; o al menos podemos afirmar que así debieron de haber pensado los antiguos, cuando aventuraron que los enemigos del tirano se habrían ido a la Grecia continental para preguntar al dios cuándo podrían librarse de un tirano tan feroz. La profecía de la Pitia se muestra, sin embargo, de signo contrario: el tirano todavía vivirá, porque se ha redimido con un acto de magnanimidad, la salvación de su conspirador. Es inútil subrayar que la imagen aquí presentada revela, sin lugar a dudas, una larga tradición en la interpretación de la figura de Falaris, en gran medida ya antigua, y en tiempos de Ateneo bien codificada: el Falaris bueno y magnánimo formó parte, sin embargo, de la tradición, como también evidentemente un veredicto de este tipo puede sugerir. 
Además los contactos en la tradición sobre la caída de las tiranías arcaicas en Sicilia, Magna Grecia y en la Grecia continental pueden probarse precisamente por la similitud de las historias de amores masculinos como causa de derribo de la tiranía. Aparte del caso más famoso de Harmodio y Aristogitón en Atenas, también el de Hiparino y Antileón en Metaponto, que parece ahora apoyado también por datos arqueológicos (Lombardo 1982: 189-205; 1998: 97-98; De Siena 2001; 2008; Rocchietti 2002; Tamburrino 2008: 6-7). Por lo tanto si la profecía, el chresmos, sirve sobre todo para otorgar un sello de autenticidad al hecho relatado, también es verdad que se introduce en un recorrido de la tradición que asigna un sitio privilegiado al veredicto oracular como guía que nos conduce por los hechos históricopolíticos.

De diferente manera puede ser, en cambio, la valoración del otro veredicto (327 Parke-Wormell = Q 85 Fontenrose), el citado 'al pie de la letra' por Ateneo y por Eliano, aunque con alguna diferencia formal. En Ateneo: «La Suerte sonríe a Caritón y a Melanipo, ejemplos de divina amistad para los efímeros mortales». En Eliano: «Ejemplo de divina amistad para los mortales fueron, hombres dichosos, Caritón y Melanipo". En Ateneo, el veredicto aparece unido a los cómplices de Caritón, aquellos cuyos nombres no quiso revelar bajo tortura. En Eliano está presente, en cambio, un genérico husteron, «sucesivamente», que otorga al relato una dimensión atemporal. Pero no querría resolver de modo simple la cuestión, como han hecho los comentaristas italianos de la traducción de Deipnosofistas de Ateneo, argumentando que es posible que la intervención de Apolo esté en relación con el hecho de que el dios, protagonista él mismo de apasionados amores homosexuales - con Admeto y con Jacinto-, protegía a las parejas de amantes (Ateneo 2001, vol. 3: 1548 n. 4). Además, el texto de Ateneo no aclara si se ha hecho una nueva consulta al oráculo o si el veredicto era relativo a la primera, la de los opositores al régimen. Se dice sencillamente que la respuesta se refiere a los amigos de Caritón, con una expresión, hoi amphi ton Charitona, que podría recordar los círculos políticos de los siglos $\mathrm{V}$ y IV a.C. Sin embargo, también la parte inicial del pasaje, con la cita de Jeronimo de Rodios (fr. 34 Wehrli), vuelve a denominar con el término hetairikon un tema político central en el helenismo de los siglos VI y V a.C. Si ya Platón (Symp. 178d-180b), inspirador de esta parte de la obra de Ateneo, puso en directa correlación la unión homoerótica con el valor guerrero, es igualmente importante subrayar que las heterias, en cuanto que grupo político, desempeñaron un papel determinante en el curso del siglo $\mathrm{V}$ a.C., como leemos en Tucídides (3.82.6; ver Ateneo 2001, vol.3: 1547-1548 n. 5 y 1549 n.3). En Ateneo, el protagonista Mírtilo subraya la importancia de la unión erótica y de amistad como estímulo para la acción política de la liberación del tirano. De hecho, hetairikon es una de las cuatro formas de la philia, "amistad», también representadas por Plutarco (Erot. 758c-d; Ateneo 2001, vol. 3: 1547-1548 n.5). Por lo tanto, la aprobación que se da a los dos enamorados-héroes afecta no solo a su relación personal sino a su papel de conspiradores contra el tirano; la 'divina amistad' y la 'felicidad' que el dios les adscribe implican quizás los dos aspectos por los que ellos están representados, aspectos en gran medida inseparables en el helenismo arcaico. 
Un último elemento a considerar es la forma de la cita oracular en Ateneo. Nuestro autor precisa que el veredicto fue pronunciado con los versos que formaban el dístico elegíaco invertidos - 'hexámetro + pentámetro' se convierten en 'pentámetro + hexámetro'-, según una forma usada más adelante por Dionisio Calco. Es bien conocido que los veredictos delficos fueron articulados por mucho tiempo en versos y también este elemento contribuyó a mantener la oscuridad y el atractivo que los caracterizaba. Pero, por otra parte, Plutarco, en De Pythiae oraculis, dice haber compuesto el pequeño tratado para explicar por qué los veredictos de la Pitia ya no están en verso, insistiendo evidentemente en el cambio de las condiciones socio-políticas y culturales como causa del empleo contemporáneo de la prosa para los veredictos. Él, de hecho, indica que, mientras en el pasado iban a consultar el oráculo ciudades, reyes y tiranos sobre importantes cuestiones políticas, militares y religiosas - por ejemplo participaciones en guerras, fundaciones de colonias, instituciones de cultos o celebraciones de sacrificios (408b-c)-, en cambio en su época, la paz y la tranquilidad empujan a limitar los problemas por los que dirigirse al dios - si está bien casarse, si está bien navegar, si está bien prestar dinero-; a lo sumo las ciudades pueden plantearse cuestiones sobre la cosecha, la cría, la salud pública. Se trata, por lo tanto, de una notable diferencia entre la solemnidad de los veredictos del pasado y la simplicidad de los problemas planteados en aquel entonces, que explica claramente la necesidad del paso del estilo poético de los antiguos oráculos al prosaico. Por otra parte, el nuevo estilo tiene la enorme ventaja de la mayor comprensión, que es, en cambio, impropia de la oscuridad y la ambigüedad reconocidas en el primitivo lenguaje oracular. Una amplia parte del diálogo de los protagonistas del tratado plutarqueo está dedicada más tarde a resolver la cuestión del valor poético de los veredictos en verso: a aquellos que defienden que la oscuridad de los versos oraculares no puede ser producto del dios dado que está en contradicción con la armonía y gracia típicas de la divinidad —como en Homero y Hesíodo (Sfameni Gasparro 2002: 12)—, se puede objetar que el dios provee exclusivamente la inspiración, mientras que las palabras vienen de las profetisas que hacen de intermediarias. Por lo tanto, el oráculo de Ateneo nos reconduce a una fase arcaica de la expresión oracular, a la cual la inversión métrica — que no está presente en Eliano- añade, sin embargo, un carácter particular.

En cambio la referencia al empleo original del dístico en Dionisio Calco es difícil de valorar. Podemos pensar que se trata de una simple referencia literaria, una costumbre de nuestro autor, pero querría, con todas las cautelas posibles, proponer también otra sugerente posibilidad. Dionisio Calco, apodado así por haber propuesto introducir en Atenas monedas de bronce en lugar de las de plata, condujo quizás la fundación de la colonia ateniense de Turios en Magna Grecia en el 444 a.C. y compuso elegías de las que quedan siete fragmentos, casi todos de argumento simposíaco - recogidos en gran parte por el propio Ateneo- y caracterizados por un lenguaje artificioso e intencionadamente oscuro (Aloni-lannucci 2007: 148). Ahora bien, es verdad que Ateneo conocia bien su producción, y sin lugar a dudas quiso hacer una comparación literaria con el texto del oráculo. Pero ¿no podría, quizás, haber considerado también el papel político de Dionisio en la 
Atenas del siglo $\mathrm{V}$ a.C., encrucijada de historias y relatos sobre la caída de las tiranías y justo en aquellos años al centro de un proceso de reelaboración de la tradición arcaica también en relación con los hechos histórico-políticos de la Magna Grecia y de Sicilia? Este interrogante no puede encontrar ciertamente respuesta en el texto de Ateneo.

En conclusión, querría resumir esquemáticamente algunos de los puntos que me parece emergen de la lectura de este episodio en relación al papel confiado al oráculo: Este texto aparece, sobre todo, conectado al veredicto oracular y es la prueba de la estabilización de la tradición sobre un Falaris 'magnánimo y clemente'; los oráculos, más o menos ficticios, podrían ser una señal del empleo de los veredictos también en el ámbito tiránico para legitimar comportamientos políticos, como se ha evidenciado a propósito del empleo propagandístico del mito de Minos y Cócalo, y de la política religiosa del tirano; la particularidad de los textos oraculares citados y la asociación con la figura de Dionisio Calco, juntamente con las referencias políticas que puntualizan el texto entero, nos reconducen quizás a la Atenas del siglo $\mathrm{V}$ a.C. y a la reelaboración de su tradición, a la cual podrían pertenecer las fuentes de Ateneo; el oráculo de Delfos, si hay necesidad de subrayarlo, representaba también un punto de referencia central para el mundo de Sicilia y de la Italia meridional y quizás tuvo un papel, si queremos también atribuir un cierto valor histórico a estos testimonios de Ateneo, en el derribo de las tiranías arcaicas; si, en cambio, pensamos que estos testimonios de las fuentes no puedan ser pruebas históricas válidas, tenemos que aceptar de todos modos que al oráculo de Delfos se le atribuyó un papel importante, al menos, en la tradición que sobre este aspecto se creó en un momento sucesivo.

Retomando, pues, las palabras de Luraghi en su volumen sobre las tiranías arcaicas de Sicilia y Magna Grecia, podemos afirmar, sin lugar a dudas, que «la tradición literaria sobre Falaris puede enseñarnos mucho sobre cómo, en una cultura todavía predominantemente oral, la memoria histórica se plasma en función de las necesidades del presente» (Luraghi 1994: 49) y, añadiría, en grados sucesivos.

\section{BIBLIOGRAFÍA}

ALONI, A. y IANNUCCI, A. (2007), L'Elegia Greca e l'Epigramma dalle Origini al 5. Secolo. Con un Appendice sulla Nuova Elegia di Archiloco, Florencia.

ARAÚJO CALDAS, M. J. de (2003), Delphi. Orakel der Maechtigen, Bonn.

ATENEO (2001), I Deipnosofisti: i Dotti a Banchetto, Roma.

BIANCHETTI, S. (1987), Falaride e Pseudo-Falaride. Storia e Leggenda, Roma.

BRAUND, D. y WILKINS, J. eds. (2000), Athenaeus and His World, Exeter.

CRAHAY, R. (1956), La Littérature Oraculaire chez Hérodote, Paris.

DE SIENA, A. ed. (2001), Metaponto. Archeologia di una Colonia Greca, Tarento.

- (2008), «Osservazioni su alcune tombe monumentali arcaiche della necropoli occidentale», Bollettino d'Arte del Ministero per i Beni e le Attività culturali 143, 1-14.

FONTENROSE, J. (1978), The Delphic Oracle: Its Responses and Operations with a Catalogue of Responses, Berkeley.

ILES JOHNSTON, S. y STRUCK, P. T. eds. (2005), Mantike. Studies in Ancient Divination, Boston. 
La caída de la tiranía de Falaris de Agrigento en Deipnosofistas de Ateneo...

LOMBARDO, M. (1982), «Antileon tirannicida nella tradizione metapontina ed eracleota», SAL 3, 189-205.

- (1998), «La democrazia in Magna Grecia», en Greco, E. ed., Venticinque Secoli dopo I'Invenzione della Democrazia, Pesto, 77-106.

LURAGHI, N. (1994), Tirannidi Arcaiche in Sicilia e Magna Grecia da Panezio di Leontini alla Caduta dei Dinomenidi, Florencia.

MILETTI, L. (2004), «L'analisi dei testi oracolari in Erodoto», en Abbamonte, G.; Conti Bizzarro, F. y Spina, L. eds., L'Ultima Parola. L'Analisi dei Testi: Teorie e Pratiche nell'Antichità Greca e Latina, Napoli, 215-230.

MURRAY, O. (1992), «Falaride tra mito e storia», en Braccesi, L. y De Miro, E. eds., Agrigento e la Sicilia Greca, Roma, 47-60.

PARKE, H. W. y WORMELL, D. E. W. (1956), The Delphic Oracle, 2 vols., Oxford.

PARKER, R. (2000), «Greek states and Greek oracles», en Buxton, R. ed., Oxford Readings in Greek Religion, Oxford, 77-108.

ROCCHIETTI, D. (2002), Aree Sepolcrali a Metaponto. Corredi ed Ideologia Funeraria fra VI e III Sec. a.C., Potenza.

SFAMENI GASPARRO, G. (2002), Oracoli, Profeti, Sibille. Rivelazione e Salvezza nel Mondo Antico, Roma.

TAMBURRINO, C. (2008), «Metaponto attraverso un'indagine archeomatica», Frankfurter elektronische Rundschau zur Altertumskunde 8, 1-18 (http://www.fera-journal.eu). 